\title{
An investigation of dapsone compliance using an isoniazid-marked formulation
}

\author{
J N A STANLEY, $*$ J M H PEARSON* \& G A ELLARD $\dagger$ \\ * Dhoolpet Leprosy Research Centre, Hyderabad 500 006, Andra \\ Pradesh, India; $\dagger$ National Institute for Medical Research, London \\ NW7 1AA, England
}

Accepted for publication 12 May 1983

\begin{abstract}
Summary In a study conducted among out-patients in Hyderabad, it was shown that the precision of the dapsone/creatinine method for monitoring dapsone compliance could be improved if patients were prescribed specially formulated dapsone capsules containing $6 \mathrm{mg}$ isoniazid as an innocuous marker. Urine samples were obtained by means of surprise home visits; the ingestion of the isoniazid marker was revealed by a simple colorimetric procedure which gives reliably positive results for about $18 \mathrm{~h}$. The study showed that such capsules were acceptable to the patients and, in the short run, were taken more regularly than the standard tablets. However, a small proportion of patients took both capsules and tablets very irregularly, indicating that poor compliance was not overcome by simply changing the dapsone formulation.
\end{abstract}

\section{Introduction}

The dapsone/creatinine ratio (D/C ratio) method has been widely used for monitoring the regularity with which leprosy patients ingest their prescribed daily dapsone treatment. ${ }^{1}$ Estimates of the overall level of dapsone compliance have been obtained by comparing the mean $\mathrm{D} / \mathrm{C}$ ratios of urine samples collected from out-patients with those from suitable groups of controls. Although such an approach has demonstrated the ubiquity of poor dapsone compliance, it suffers from 3 important limitations:

1 Because of the lack of specificity of simple colorimetric procedures for determining dapsone and the presence of interfering compounds in normal urine samples, such samples appear to have significant dapsone concentrations. Thus in order to assess the compliance of out-patients, the apparent $\mathrm{D} / \mathrm{C}$ ratios of untreated controls must also be determined.

2 Because of the relatively slow elimination of dapsone ${ }^{2}$ and its metabolites 
from the body (half-life about $27 \mathrm{~h}$ ), D/C ratios typical of those of fully compliant patients are only reliably achieved after giving some 4 consecutive supervised daily dapsone doses; this normally requires access to hospitalized patients.

3 Although determining $\mathrm{D} / \mathrm{C}$ ratios virtually eliminates the effect of diuresis on interpreting dapsone urine tests, ${ }^{3}$ there are considerable individual differences in creatinine excretion rates, and for this reason the $\mathrm{D} / \mathrm{C}$ ratios of urine samples collected from supervised controls typically vary over a 3 -fold range. ${ }^{4-7}$ It is therefore not possible to detect the omission of single dapsone doses or to assess how many doses have been missed, unless the $\mathrm{D} / \mathrm{C}$ ratios of individual patients are first established during fully supervised treatment.

Recent investigations have demonstrated the feasibility of using minute doses of the antituberculosis drug isoniazid (INH) as an innocuous marker for studying the compliance of drugs prescribed for daily self-administration. ${ }^{8,}{ }^{9}$ Since INH is white, tasteless and odourless, preparations tagged with milligram amounts of the drug should be indistinguishable from standard formulations, while world-wide experience in the treatment of tuberculosis testifies to the safety of INH at daily doses of $300 \mathrm{mg}$ when given for periods of at least a year. ${ }^{10,11}$ The ingestion of such INH doses can be demonstrated using a simple colorimetric urine-test procedure for its metabolites isonicotinic acid and isonicotinylglycine. Studies conducted among volunteers showed that $6 \mathrm{mg}$ doses of INH gave reliably positive urine-test results up to about $18 \mathrm{~h}$ and uniformly negative results from $48 \mathrm{~h}$ onwards. ${ }^{9}$

It was therefore anticipated that a much more precise evaluation of dapsone compliance might be obtained by employing capsules tagged with $6 \mathrm{mg} \mathrm{INH}$, since if the daily doses were recommended to be taken first thing each morning, the finding of a negative urine-test result would unequivocally indicate failure to have taken a dose that day. This paper describes a study of dapsone compliance among out-patients in Hyderabad, India to investigate the potentialities of such an approach and to compare the acceptability of INH-marked dapsone capsules with standard dapsone tablets.

\section{Methods}

PATIENTS AND SAMPLES

The investigation was conducted among a group of patients living within $6 \mathrm{~km}$ of Dhoolpet Leprosy Research Centre and typical of those registered for treatment there. Patients were only excluded from the study on 4 grounds:

1 If they had been treated for less than a year, since the compliance of such patients might be anticipated to be atypically good. ${ }^{7}$

2 If they had a record of habitual irregular attendance, since it seemed unreasonable to include those who might be extremely difficult to contact 
regularly or who might take too few of their prescribed capsules or tablets for comparison of their acceptability to be possible.

3 If they were being treated with other drugs.

4 If there was any suggestion that they might be suffering from undiagnosed tuberculosis.

During the course of a routine clinic visit patients were interviewed, the study explained and they were asked if they would be willing to have clinic staff visit their homes approximately once a week to collect a urine sample. The study was presented as an investigation of treatment with a new capsule with urine tests being undertaken to evaluate its effectiveness.

When a patient agreed to participate in the study, his/her home address was obtained and shortly thereafter an initial home visit was undertaken. After locating the patient's dwelling, the patient and family were interviewed and their willingness to participate in the study verified. A urine sample was obtained at this visit. Inclusion in the study was finally confirmed by finding the patient at home and collecting a further urine sample on the next visit, and the investigation was initiated by giving the patient the first month's supply of tablets or capsules for daily self-administration immediately on rising each morning.

Twenty male and 14 female patients were included in the study. They were aged from 15 to 73 years (mean 37 years), weighed from 31 to $68 \mathrm{~kg}$ (mean $46 \mathrm{~kg}$ ) and had been previously treated for up to 16 years (mean 5 years). They were randomly allocated to receive daily treatment with standard dapsone tablets (100 $\mathrm{mg}$ ) for 8 weeks, followed by INH-labelled dapsone capsules (100 mg dapsone plus $6 \mathrm{mg}$ isoniazid) for 8 weeks, or vice versa. The stocks of dapsone tablets or capsules were delivered every 4 weeks. Urine samples were collected by means of weekly surprise home visits between 7 a.m. and 12 noon which followed a randomized schedule so that patients did not know when they would next be visited. If they were out at the time, their homes were revisited later that day and, if necessary on the following day also. Urine samples were stored at $0-4{ }^{\circ} \mathrm{C}$ in plastic containers to which a crystal of thymol had been added until shipment by air (without refrigeration) to London for subsequent analysis.

\section{ANAL YTICAL METHODS}

$\mathrm{D} / \mathrm{C}$ ratios were estimated by determining the urinary concentrations of dapsone plus its diazotisable metabolites (as dapsone equivalents) and creatinine by modifications of the Bratton and Marshall and alkaline picrate procedures, respectively. ${ }^{12}$ Urine samples were tested for the presence of the INH metabolites isonicotinic acid and isonicotinylglycine by pipetting aliquots $(0.5 \mathrm{ml})$ into small test-tubes together with $0.2 \mathrm{ml} 4 \mathrm{M} \mathrm{pH} 5.0$ acetate buffer and reacting by the sequential addition at 15 -s intervals of $0 \cdot 1 \mathrm{ml} 10 \%$ aqueous potassium cyanide, $0 \cdot 1$ $\mathrm{ml} \mathrm{10 \%}$ aqueous chloramine-T and $0.5 \mathrm{ml} \mathrm{1 \%}$ barbituric acid in acetone/water 
$(1: 1 \mathrm{v} / \mathrm{v})$. A positive result was indicated by the appearance within $30 \mathrm{~min}$ of a blue, green or grey colour depending on the natural background colour of the urine sample. Samples from patients who regularly smoked or chewed tobacco of ten gave characteristic orange colours after reaction presumably due to the excretion of metabolites of nicotine. Among such patients ingestion of isoniazidmarked dapsone capsules was indicated by urine samples which on reaction gave grey or brown rather than orange colours.

\section{Results}

COMPARISON OF OVERALL D/C RATIOS DURING TREATMENT WITH TABLETS OR CAPSULES

Analyses could only be carried out on a total of 320 urine samples, 187 collected while patients were prescribed standard dapsone tablets and 133 during treatment with the INH-marked capsules, because about a third of those originally collected were lost on account of faulty packing during shipment to England. The mean $\mathrm{D} / \mathrm{C}$ ratios ( $\mu \mathrm{g}$ apparent dapsone/mg creatinine) of these two sets of samples averaged $83 \pm 37$ and $92 \pm 37$, respectively $(0 \cdot 025<P<0 \cdot 05)$.

INGESTION OF INH-MARKED DAPSONE CAPSULES, ESTABLISHMENT OF 'COMPLIANT' D/C RATIOS AND INTERPRETATION OF OTHER D/C RATIOS

The $\mathrm{D} / \mathrm{C}$ ratios of the 320 urine samples are set out in Table 1. Four-fifths $(108 / 133)$ of the urine samples collected during the time that the patients were issued with INH-marked dapsone capsules gave positive tests for isonicotinic acid indicating that at least one such capsule had been swallowed during the previous $48 \mathrm{~h}$. The arithmetic mean $\mathrm{D} / \mathrm{C}$ ratios of such samples are hereafter referred to as 'mean compliant' $\mathrm{D} / \mathrm{C}$ ratios. Positive isonicotinic acid tests were not obtained from 3 patients during the period that dapsone capsules were prescribed (numbers 3, 21 and 28). Approximate estimates of their mean compliant $\mathrm{D} / \mathrm{C}$ ratios were therefore obtained by averaging their obviously clustered higher $\mathrm{D} / \mathrm{C}$ ratios when dapsone tablets were given (see Table 1). For clarity the data are presented in order of increasing mean compliant ratios. These ranged from 56 to 152 and averaged 91 and 117 for the 20 male and 14 female patients, respectively $(P<0.001)$. With the exception of the results from patient 6 , which will be considered below, there was a marked tendency for the compliant $\mathrm{D} / \mathrm{C}$ ratios of individuals to cluster together, their variation about the mean being equivalent on average to only $\pm 12 \%$. This clustering of individual compliant $\mathrm{D} / \mathrm{C}$ ratios is similar to that encountered previously when successive urine samples were collected immediately before a series of daily supervised dapsone doses. ${ }^{4}$

The great majority of urine samples were collected between about 8 and 11 in 


\begin{tabular}{|c|c|c|c|c|c|c|c|}
\hline \multirow[b]{2}{*}{ Patient } & \multicolumn{2}{|c|}{$\begin{array}{l}\text { Compliant ratios } \\
\text { Marked capsule ingested* }\end{array}$} & \multirow[b]{2}{*}{ Tablet ingested $\dagger$} & \multicolumn{4}{|c|}{ Number of missed doses $\dagger$} \\
\hline & Individual & Mean $\pm S D$ & & 1 & 2 & 3 & $\geqslant 4$ \\
\hline 1 & $58,57,54$ & $56 \pm 2$ & $86,64,62,52$ & $32, \mathbf{3 0}+$ & & & $8,7,7$ \\
\hline 2 & $86,83,80,76,65,62$ & $75 \pm 10$ & 80 & 48,42 & 22 & & \\
\hline 3 & & $(7 \overline{7}) \S$ & $94,79,76,71,64$ & 39,34 & & & \\
\hline 4 & $84,77,71$ & $77 \pm 9$ & $82,76,66$ & 50 & 29 & & \\
\hline 5 & $83,77,76,74$ & $78 \pm 4$ & 62 & 52,49 & $\mathbf{3 2}, \mathbf{3 2}, 25$ & 17 & $11,11,8$ \\
\hline 6 & $86,86,84,78,73,61,(253,222)^{\bullet}$ & $78 \pm 10$ & $93,71,69,67(158,147)^{* *}$ & & & & \\
\hline 7 & $81,79,75$ & $78 \pm 3$ & $128,109,90,89,87,78,70$ & 38 & & & \\
\hline 8 & $97,86,79,79,75,74,72$ & $80 \pm 9$ & $108,95,90,82,72,71$ & & & & 11 \\
\hline 9 & 88,80 & $84 \pm 6$ & 75 & $\mathbf{5 3}, 53$ & & & \\
\hline 10 & $94,91,68$ & $84 \pm 14$ & & 53,38 & & 18 & \\
\hline 11 & 94,77 & $86 \pm 12$ & 82,71 & 57,45 & & & \\
\hline 12 & $108,93,84,63$ & $87 \pm 19$ & $99,92,78,72,70,69$ & 61,42 & & & \\
\hline 13 & 106,71 & $89 \pm 25$ & $100,87,85,71,70,70,68$ & 54,50 & & & \\
\hline 14 & $100,93,92,84$ & $92 \pm 7$ & $102,89,84,83,78,71$ & $68,49,43$ & & & \\
\hline 15 & $124,104,85,83,76$ & $94 \pm 20$ & $97,93,85$ & & & & \\
\hline 16 & $101,100,100,100,100$ & $100 \pm 0$ & & 64 & & 25 & 14 \\
\hline 17 & $111,103,102$ & $105 \pm 5$ & & 67,46 & $41,39,32$ & & $9,5,3$ \\
\hline 18 & 108 & 108 & $179,145,133,123,111,103$ & & & & \\
\hline 19 & $123,113,106,101,98$ & $108 \pm 10$ & & $66,63,62,55$ & & & \\
\hline 20 & $114,111,101$ & $109 \pm 7$ & $103,102,102,92$ & 79,77 & & & \\
\hline 21 & & $(109) \S$ & $154,122,117,110,108,101,80,79$ & & & & \\
\hline 22 & 112 & 112 & $162,156,153,122,122,117$ & 83 & & & \\
\hline 23 & 124,102 & $113 \pm 16$ & $128,128,119,87$ & 71 & & & \\
\hline 24 & 127,102 & $115 \pm 18$ & $123,104,104,102,99,98$ & 54 & & & \\
\hline 25 & $126,123,117,113,96$ & $115 \pm 12$ & $129,125,124,116,116,110,108,104$ & & & & \\
\hline 26 & 127,106 & $117 \pm 15$ & 92 & $81,80,59$ & 49,48 & & \\
\hline 27 & $132,120,119,117,113,100$ & $117 \pm 10$ & & $81,71,70,65,57,55$ & 39,35 & & \\
\hline 28 & & $(119) \S$ & 133,105 & 57 & 49 & 26,25 & \\
\hline 29 & 134,107 & $121 \pm 19$ & & $75,67,55$ & & & \\
\hline 30 & $150,147,132,127,122,97$ & $129 \pm 19$ & 111,110 & 84 & & & \\
\hline 31 & $173,121,101$ & $132 \pm 37$ & 116,103 & $\mathbf{8 9}, 82,73,71$ & 47,34 & 31 & 8 \\
\hline 32 & 137 & 137 & $154,144,132,132.120,109$ & 101 & & 32 & \\
\hline 33 & $173,148,107$ & $143 \pm 33$ & $161,139,136,134,125,115$ & 84 & & & \\
\hline 34 & 156,147 & $152 \pm 6$ & & $87,81,78,68$ & & & \\
\hline
\end{tabular}

* Obtained when urine samples gave positive isonicotinic acid tests. $\quad$ † For basis of interpretation see text. $\quad$ Bold type when capsules were prescribed, normal type when tablets were given. § Approximate estimate (see text). T Triple doses assumed to be taken. $\quad * *$ Double doses assumed to be taken. 
the morning. It therefore follows that a positive isonicotinic acid urine test would normally be due to a marked capsule having been swallowed either less than $5 \mathrm{~h}$ previously (earlier that morning) or more than $10 \mathrm{~h}$ before (the previous day). The small variability in the compliant $\mathrm{D} / \mathrm{C}$ ratios consequently indicates that most positive isonicotinic acid urine-test results were due to a single marked capsule having been swallowed earlier in the morning that the urine sample was collected.

The one exception to these findings (the results for patient 6) were especially interesting. During treatment with the INH marked capsules all 8 of his urine samples gave positive isonicotinic acid tests results, indicating excellent compliance. However, while the $\mathrm{D} / \mathrm{C}$ ratios of 6 of the samples were closely clustered (range 61 to 86, mean 78), those of the remaining two were 3 times higher (222 and 253), indicating that on those occasions he had ingested $300 \mathrm{mg}$ of dapsone. In addition 2 tests while on tablets showed levels twice as high as the compliant ratios (147 and 158), indicating that he had taken $200 \mathrm{mg}$ of dapsone on each of those 2 days.

It was possible to obtain an approximate estimate of the numbers of dapsone doses that had been missed prior to the home visits by comparing the $\mathrm{D} / \mathrm{C}$ ratios of each urine sample with the mean compliant $\mathrm{D} / \mathrm{C}$ ratio for the patient. Thus it was assumed that in the average patient, after correcting for the contribution of natural diazotisable compounds in the urine (equivalent to a blank $\mathrm{D} / \mathrm{C}$ ratio of about 6 ), D/C ratios would fall by about $50 \%$ every $27 \mathrm{~h} .{ }^{3} \mathrm{D} / \mathrm{C}$ ratios would therefore be expected to decline to about $73 \%$ after $12 \mathrm{~h}, 40 \%$ after $36 \mathrm{~h}, 21 \%$ after $60 \mathrm{~h}$ and $12 \%$ after $84 \mathrm{~h}$. Hence among the isonicotinic acid negative samples corrected $\mathrm{D} / \mathrm{C}$ ratios of more than $73 \%$ of the mean corrected compliant ratios were taken as indicating that the daily dose of standard dapsone tablets had been taken as prescribed, whereas values of $40-73 \%, 21-40 \%, 12-21 \%$ and less than $12 \%$ were interpreted as implying that either $1,2,3$ or 4 or more doses, respectively, of capsules or tablets had been missed.

\section{RELATIVE ACCEPTABILITY OF CAPSULES AND TABLETS}

Table 2 shows the estimated number of doses of dapsone capsules or tablets that were missed by the 34 patients. It was apparent that the capsules were more regularly self-administered (133 tests, 39 doses missed) than the normal tablets (187 tests, 119 doses missed). Each patient failed on average to take about 3-4 dapsone tablets but only missed 1 capsule. Moreover when individual patients were reviewed, only 2 appeared to take their tablets more regularly.

\section{VARIABILITY OF DAPSONE COMPLIANCE}

Patients differed greatly in the regularity with which they ingested their dapsone capsules and tablets (Table 3). Thus the compliance of 10 of the 34 patients was excellent, the urine test results indicating that they had missed at the most only a 
Table 2. Relative acceptability of dapsone capsules and tablets

\begin{tabular}{|c|c|c|c|c|}
\hline \multirow{2}{*}{$\begin{array}{l}\text { Interpretation of urine tests, } \\
\text { no. of missed doses }\end{array}$} & \multicolumn{2}{|c|}{$\begin{array}{l}\text { No. of samples } \\
\text { tested }\end{array}$} & \multicolumn{2}{|c|}{$\begin{array}{c}\text { Total no. of missed } \\
\text { doses }\end{array}$} \\
\hline & Capsules & Tablets & Capsules & Tablets \\
\hline None & 108 & 119 & 0 & 0 \\
\hline One & 17 & 42 & 17 & 42 \\
\hline Two & 4 & 11 & 8 & 22 \\
\hline Three & 2 & 5 & 6 & 15 \\
\hline Four (or more) & 2 & 10 & 8 & 40 \\
\hline Total & $\overline{133}$ & $\overline{187}$ & $\overline{39}$ & $\overline{119}$ \\
\hline
\end{tabular}

Table 3. Variability of dapsone compliance

\begin{tabular}{|c|c|c|c|c|c|}
\hline \multirow[b]{2}{*}{ Compliance } & \multirow[b]{2}{*}{ No. of patients } & \multirow[b]{2}{*}{ No. of tests } & \multicolumn{3}{|c|}{ No. of missed doses } \\
\hline & & & Capsules & Tablets & Total \\
\hline Excellent & 10 & 97 & 1 & 4 & 5 \\
\hline Average & 19 & 167 & 15 & 57 & 72 \\
\hline \multirow[t]{2}{*}{ Poor } & 5 & 56 & 23 & 58 & 81 \\
\hline & - & - & - & - & 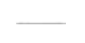 \\
\hline Total & 34 & 320 & 39 & 119 & 158 \\
\hline
\end{tabular}

single dose of dapsone. By contrast the compliance of patients 1, 5, 17, 28 and 31 was very poor, whether they were prescribed capsules or tablets, with individual totals of missed dapsone doses ranging from 9 to 23 . These 5 patients accounted for about a half of the missed capsule and tablet doses in the whole study. The remaining 19 patients missed on average a single dose of the marked capsules and 3 doses of dapsone tablets. Among this relatively small group of patients dapsone compliance appeared not to be influenced by either age, sex or duration of treatment.

\section{Discussion}

Previous studies using the $\mathrm{D} / \mathrm{C}$ ratio method to assess the compliance of patients with their prescribed treatment have usually been cross-sectional in design with the ratios of a group of out-patients being compared with those of groups of fully 
supervised hospitalized patients and untreated controls. The present study, however, differed from such studies in 3 important respects:

1 Urine samples were obtained from out-patients by unannounced home visits rather than on the occasion of their attendance at a routine clinic. Surprise home visits should yield results more typical of the patients' general compliance than findings based on samples collected at clinic visits. In the latter situation compliance estimates could be positively biased if the forthcoming visit reminded the patient to take his treatment. Alternatively negative bias could arise if the clinic visit were prompted by the patient having finished his stock of dapsone tablets.

2 The study tried to assess whether dapsone-containing capsules would be as acceptable to patients as their normal dapsone tablets and whether, if such a formulation were regarded as 'new treatment', it might even improve their compliance. It showed conclusively that such capsules were acceptable to the patients and demonstrated that, at least in the short run, they were actually taken more regularly than the standard tablets. However, the extremely irregular self-administration of both capsules and tablets by 5 of the 34 patients showed that the problems of poorly compliant patients cannot be overcome by simply changing the dapsone formulation.

3 By utilizing dapsone capsules containing a $6 \mathrm{mg}$ marker dose of $\mathrm{INH}$, testing for their ingestion by the simple colorimetric isonicotinic acid procedure and comparing the $\mathrm{D} / \mathrm{C}$ ratios of samples giving either positive or negative isonicotinic acid results, it was possible to assess the regularity with which patients ingest their prescribed dapsone with much greater precision than was formerly attainable. Such an approach clearly showed that the capsules were being taken more regularly than the tablets, a conclusion which could only be hinted at on the basis of a simple comparison of the mean $\mathrm{D} / \mathrm{C}$ ratios during the two treatments, and demonstrated in a very compelling way the great variability in individual dapsone compliance.

As a result of this investigation one can envisage a much improved standard approach to monitoring the dapsone compliance of out-patients. Patients would be given an initial course of daily treatment with INH-marked dapsone capsules or tablets, to be taken at home at the usual time. During this period several urine samples would be collected by means of clinic or home visits. Af ter testing for the ingestion of the marker by the isonicotinic acid procedure, the $\mathrm{D} / \mathrm{C}$ ratios of those giving positive results would be determined. Once a reliable estimate of the individual's mean compliant $\mathrm{D} / \mathrm{C}$ ratios had been obtained, treatment would be continued with ordinary dapsone tablets. The patients' compliance would then be followed by collecting further urine samples and comparing their $\mathrm{D} / \mathrm{C}$ ratios with the mean compliant value. Such an approach would minimize the slight risk that repeated ingestion of marker doses of INH by an individual with unsuspected tuberculosis might lead to the selection of INH-resistant tubercle bacilli and 
thereby prejudice subsequent treatment with INH-containing regimens. ${ }^{8}$ It would also be an economical way of using limited stocks of specially formulated INH-marked dapsone capsules or tablets.

\section{Acknowledgments}

We wish to thank the International Dispensary Association, Amsterdam, The Netherlands, for the gift of the INH-marked dapsone capsules which were specially prepared for this study. The home visits were undertaken by Mr Paul Sukumar, Mrs Deveena Prabhaker and Mr Syed Yousuff Jani. J M H Pearson is a member of the staff of Victoria Hospital, Dichpalli, on secondment from the National Institute for Medical Research, London. Dhoolpet Leprosy Research Centre is managed by Victoria Hospital, Dichpalli, in collaboration with the Medical Research Council (of Great Britain), and also receives support from the British Leprosy Relief Association.

\section{References}

1 Ellard GA. Drug compliance in the treatment of leprosy. Lepr Rev, 1981; 52: 201-13.

2 Colston M J, Ellard GA, Gammon PT. Drugs for combined therapy: experimental studies on the antileprosy activity of ethionamide and prothionamide, and a general review. Lepr Rev, 1978; 49: $115-26$.

${ }^{3}$ Ellard GA. Profile of urinary dapsone/creatinine ratios af ter oral dosage with dapsone. Lepr Rev, 1980; 51: 229-36.

${ }^{4}$ Low SJM, Pearson JMH. Do leprosy patients take dapsone regularly? Lepr Rev, 1974; 45: 218-23.

5 Jesudasan K, George B, Chacko CJG, Taylor PM, Kurian PV, Job CK. An evaluation of the self-administration of DDS in Gudiyatham Taluk. Lepr India, 1976 (Suppl); 48: 668-76.

${ }^{6}$ Cates CJ. An assessment of dapsone self-administration in Gudiyatham Taluk. Lepr Rev, 1981; 52: 55-64.

7 Barton RPC, Rees RJW, McDougall AC, Ellard GA. The nose in lepromatous leprosy: Bacteriological and histological studies of patients treated with dapsone monotherapy for varying periods of time. Int $J$ Lepr, 1982; 50: 58-67.

${ }^{8}$ Ellard GA, Jenner PJ, Downs PA. An evaluation of the potential use of isoniazid, acetylisonizid and isonicotinic acid for monitoring the self-administration of drugs. Br J clin Pharmac, 1980; 10: $369-81$.

9 Ellard GA, Jenner PJ, Allen BW. Who is taking their tablets? Br Med J, 1982; ii: 1660-1.

${ }^{10}$ Fox W. General considerations in the choice and management of regimens of chemotherapy for pulmonary tuberculosis. Bull Int Un Tuberc, 1972; 47: 49-67.

11 Girling DJ. The hepatic toxicity of antituberculosis regimens containing isoniazid, rifampicin and pyrazinamide. Tubercle, 1978; 59: 13-32.

12 Ellard GA, Gammon PT, Helmy HS, Rees RJW. Urine tests to monitor the self-administration of dapsone by leprosy patients. Amer J Trop Med Hyg, 1974; 23: 464-70. 